\title{
MODULARIDAD, EVOLUCIÓN Y ONTOLOGÍA RELIGIOSA
}

\section{Dr. Juan Carlos Vélez*}

En este trabajo sostengo otra manera de comprender el fenómeno religioso desde la ontología religiosa que no excluye la ciencia, particularmente las Ciencias Cognitivas. La teoría de la modularidad de la mente y la psicología evolutiva arrojan luz sobre el origen del dualismo y la teleología que subyace a la manera en que las mentes hospedaron algunas de las creencias religiosas. Sostengo, desde el naturalismo de Dennett, Boyer y Dawkins, que el fenómeno religioso no es una adaptación biológica de nuestros cerebros, en términos psicológicos, sino que es un subproducto de estos que en interacción con el entorno ha sido diseñado para otras actividades, principalmente aquellas que tienen que ver con la predicción de nuestra la conducta, la de otros seres vivientes y fenómenos naturales, en dirección a la supervivencia de nuestra especie.

Palabras clave: Modularidad, evolución, cognición, adaptación, naturalización, religión.

\section{MODULARITY, EVOLUTION AND RELIGIOUS ONTOLOGY}

In this paper I propose a way to understand the religious phenomenon from religious ontology without excluding science, particularly the Cognitive Sciences. The theory of the modularity of the mind and evolutionary psychology help us understand the origin of dualism and the teleology underlying the way in which minds hosted some religious beliefs. I will argue, from the naturalism of Dennett, Boyer and Dawkins, that religious phenomena are not a biological adaptation but a by-product of psychological mechanisms designed for other activities, such as prediction of our behavior and understanding of other living beings and natural phenomena.

Keywords: Modularity, evolution, cognition, adaptation, naturalization, religion.

\footnotetext{
*Universidad Autónoma de Occidente, Cali, Colombia. Correo electrónico: karlegion@yahoo.es
} 

$-$

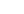




\section{Introducción}

¿A QUÉ SE DEBE EL HECHO DE LA PROLIFERACIÓN DE LA RELIGIÓN EN NUESTRO siglo marcado, en gran medida, por significativas dosis de comprensión científica del mundo?, ¿por qué en nuestra época posdarwiniana las personas siguen viviendo sus vidas en torno a creencias sin evidencia científica? Todos los sistemas religiosos, en mayor o menor medida, ganan terreno a pesar de que las implicaciones del darwinismo han logrado acorralar importantes espacios explicativos de nuestro pasado remoto. Como resultado de ello, algunos científicos como Stephen Jay Gould sostienen que la religión se ocupa de asuntos cuyas temáticas y propósitos no son los mismos que los de la ciencia, por tanto, sus ámbitos y dominios deben mantenerse en una especie de tregua suspendida en la diplomacia pragmática de mundos antagónicos. Pero en medio de esa tregua surge entonces la pregunta: ¿puede la ciencia explicar el origen de las creencias religiosas?, e incluso más apremiante aún, ¿debería hacerlo?

Pese a todo, desde hace algún tiempo la religión está siendo abordada desde disciplinas como la sociología, la etnografía, el psicoanálisis, y más recientemente la sociobiología, la antropología y la psicología evolutiva. Podemos considerar que ya las creencias religiosas no son objeto de estudio de las interpretaciones de las ciencias sociales y humanas, sino que hay una demanda creciente de explicación científica que ha debilitado continuamente su inmunidad teórica. La antropología social o la psicología, aunque han hecho importantes sugerencias hacia la comprensión del fenómeno religioso, se han quedado en la superficie de las descripciones de los rasgos más sobresalientes, pero no las causas de estos. Entre las explicaciones más frecuentes acerca de por qué existe la religión tenemos: i) que es una extensión y/o analogía del orden social dominante; ii) que actúa como un placebo que prolonga la vida mediante la reducción del estrés; iii) que satisface nuestra curiosidad acerca del lugar que ocupamos en el universo, dándole significado a la vida; iv) que es el resultado intencional de un grupo de personas, una herramienta utilizada por la clase dirigente para subyugar las masas (son bien conocidas las teorías de Marx y Feuerbach); v) que consuela a las personas frente a las vicisitudes de la vida; vi) que consiste en el funcionamiento de un nodo especializado en el cerebro, lo cual supone una explicación adaptativa de este (aquí entran disciplinas recientes como la neuroteología y la bioteología); vii) que promueve la selección de grupo, es decir, entra aquí todo el problema del altruismo, mecanismo de cooperación que exhiben algunas especies para perpetuarse; y por último, (viii) que consiste en un subproducto del cerebro que ha evolucionado para otras funciones. En esta última hipótesis es en la que nos concentraremos, pero antes de ello presentaré un breve repaso de los rasgos más sobresalientes de la religión desde la perspectiva de la reflexión o creencia sobre Dios o los dioses, puesto que el núcleo de 
toda religión es la creencia en entidades sobrenaturales. En lo que sigue, me basaré en el libro Módulo de filosofía moderna y contemporánea publicado por los profesores William González y Alexander Muñoz en el año 2003.

Los estudios sobre la religión en Grecia han sido y siguen siendo más complejos de lo que suele llegar a suponerse, pues estos señalan la diversidad de elementos que entran en juego como rasgos de tipo cívico, escatológico, mítico y retazos de pequeñas religiones provenientes de Oriente; sin embargo, se pueden extraer algunos rasgos fundamentales. Por ejemplo: la inexistencia de un texto sagrado o un personaje canónico que sirva de núcleo blindado hace que no pueda fijarse creencias y comportamientos de los individuos de manera normativa. Los poemas de Homero y Hesíodo no tenían el carácter de sagrados en el sentido de que estos textos eran permeables a críticas y nadie era acusado por ello.

El segundo tópico a considerar es el antropomorfismo psicológico de los dioses olímpicos. Términos intencionales tales como deseos, pasiones, engaños, creencias son compartidos tanto por dioses como por hombres, lo cual no les hace precisamente modelos de conducta. Dada esta consideración, algunos autores incluso han señalado que los mitos griegos tuvieron como referencia la existencia real de seres humanos, reyes, gobernantes cuya condición de vida se habría malinterpretado. Además hay que indicar que ya algunos filósofos de la antigüedad -como Protágoras-dudaron de la existencia de los dioses al afirmar que dada la breve existencia humana no era posible acceder al conocimiento de los dioses.

Según Platón, tanto el mundo como nuestra alma inmortal son obra del Demiurgo que, a manera de artesano, los ha creado a partir de materia, y ello es lo que explica la imperfección del mundo material en contraposición a la perfección del modelo utilizado, es decir, las ideas asimismo preexistentes. La rama fundamental de la filosofía, según Aristóteles, es la teología, ya que refiere al conocimiento de Dios, quien es la explicación del movimiento del mundo. Todas las cosas, dice el discípulo de Platón, se mueven con una finalidad que casi siempre coincide con un bien, y si este bien es perfección, en consecuencia, es finalidad hacia Dios.

Para Epicuro, al igual que para Aristóteles, Dios existe pero no se entromete en los asuntos humanos; tampoco ha creado este mundo, y por ello es inútil temer a castigos y venganzas divinos. Los dioses, según Epicuro, tienen apariencia humana y eventualmente se manifiestan en los sueños. Por otro lado, los estoicos identificaron a los dioses con fuerzas naturales, pues para estos los dioses eran la materia constituida por dos principios: una sustancia material y un fuego racional. Dios es entonces el alma de un universo vivo que se rige por leyes naturales a las que los seres humanos estamos sujetos.

Durante la época medieval, el mundo fue mirado con desdén, ya que este era considerado un riesgo para la salvación del alma inmortal. Es bien conocido el surgimiento en 
esta época de los primeros padres de la iglesia cristiana quienes basaron sus reflexiones sobre la Biblia en conceptos de los filósofos antiguos ${ }^{1}$. No obstante, no hay que perder de vista que la vida cristiana tiene como finalidad fundamental la salvación del alma mediante la fe, y por tanto, prohíbe en muchos casos el uso de la razón argumentando que fue el diablo quien sembró en los seres humanos el deseo de ciencia. También durante esta época se concentraron esfuerzos en demostrar la existencia de Dios con ingeniosos argumentos, la mayoría de carácter retórico, como el de San Anselmo, quien decía que como la existencia es una perfección y un ser perfecto tiene todas las perfecciones, entonces el ser perfecto que es Dios debe existir; y no hay que olvidar las cinco vías de Santo Tomás, quien, inspirado en Aristóteles, multiplica el argumento del motor inmóvil del Estagirita. Aunque lo anterior no agota la complejidad del pensamiento cristiano con todas sus tonalidades, para mi propósito basta y servirá de introducción para lo que sigue.

En el periodo conocido como la Modernidad, solo baste decir que el nacimiento de la ciencia matemática genera novedosos cuestionamientos sobre la religión y la reflexión sobre Dios. Por un lado, los grandes sistemas metafísicos, como los de Descartes y Leibniz, identificaron a Dios con la geometría o el orden universal (matemático), y, por otro lado, se cuestionará más radicalmente el conocimiento sobre Dios mediante el método inductivo propio del empirismo humeano, al reducir el origen de las ideas a la experiencia sensible.

En nuestra denominada época contemporánea, Cassirer advirtió que había una diferenciación gradual que va desde el mito hasta la religión, pasando por las religiones primitivas. Bajo la consideración de homo simbolicus el ser humano se ha distanciado del animal a causa de la posesión de un sistema de símbolos que ha generado el lenguaje, lo que a su vez permitió el advenimiento de rasgos culturales como el mito, la religión, el arte, la historia y la ciencia. Dice en su Antropología filosófica que las religiones monoteístas se concentran en el problema del bien y el mal, pero, a diferencia del mito que lo hacía desde fuerzas emocionales, la religión lo hace desde fuerzas morales racionales. Según su análisis, la naturaleza es concebida como la esfera de la ley y la legitimidad, lo que demuestra su origen divino ${ }^{2}$. Y es justamente ese origen divino el que va a cuestionar Cassirer, pues para este autor la religión es un producto de la cultura generado por la naturaleza simbólica del ser humano; sin embargo, plantea un hiato insalvable que dejaría, en un extremo, el origen biológico del hombre y, en el otro, su aspecto cultural. Es decir, al admitir que la teoría de la evolución ha destruido los límites de las diversas formas de vida, que hay solo una corriente continua ininterrumpida de la vida, surge la pregunta de si es posible una explicación general, unos principios biológicos que rijan el mundo orgánico y el mundo cultural. ¿Se puede reducir el mundo cultural a un pequeño número de causas generales? La respuesta de Cassirer será negativa.

1 Cfr. Copleston, Frederick, Filosofía Medieval. De San Agustín a Escoto, en Historia de la Filosofía, Tomo II, Ariel, Barcelona, 1971.

2 No es posible hacer justicia aquí al exhaustivo análisis que hace el autor. Remito al lector a CASsirer, Ernst, “Mito y Religión”, en Antropología Filosófica, Fondo de Cultura Económica, México, 1944. 


\section{Rasgos generales de la religión}

Dentro de las características generales de casi todas las religiones, especialmente las religiones que provienen de Abraham, están los siguientes: i) la creencia en seres sobrenaturales; ii) la sobrevivencia del componente inmaterial de una persona ${ }^{3}$, o en otras palabras, la defensa de una perspectiva dualista de la realidad; iii) la naturaleza especial de algunas personas para establecer vínculos especiales con agentes sobrenaturales (aquí vienen todos los estudios antropológicos sobre los hechiceros, magos, chamanes y las relaciones de sentido que otorgan estas personas a los pobladores de una comunidad); y iv), muy ligado con el punto anterior, que los rituales comportan una forma de alterar el orden natural; se habla entonces de lo sobrenatural, incluso los deístas dirán que es la intervención divina mediante el milagro.

Todos estos rasgos, y quizás algunos otros, son comunes a las grandes religiones exceptuando, por ejemplo, al budismo, que más que una religión es una forma moral de vida. De todas formas en este apartado surgen muchos interrogantes: ¿cuál fue el suelo psicológico donde nace la religión?, ¿las similitudes entre religiones se deben a que las ideas religiosas surgieron de una idea ancestral común, transmitida por generaciones mientras las personas poblaban el mundo?

\section{Algunas palabras sobre el naturalismo en filosofía}

Como en este trabajo abogo por un enfoque natural de la religión, que se asienta, si se quiere, sobre una filosofía naturalizada, me referiré rápidamente a lo que entiendo por naturalismo. El proyecto de naturalización proviene de la tesis de la indeterminación de la

3 El dualismo es la doctrina filosófica, iniciada por las religiones antiguas, mantenida por los filósofos griegos y medievales, y desarrollada especialmente por Descartes, que supone que la naturaleza constitutiva de la realidad es de dos tipos: espiritual y física. En relación a la filosofía, las preguntas problemáticas a esta cosmovisión son del tipo: ¿qué relación existe en una persona entre su mente y su cuerpo?, concretamente, ¿qué es un cuerpo humano? Y ¿qué es una mente humana? Incluso en el lenguaje cotidiano, usualmente nos expresamos mediante frases como "tiene una mente despejada", "tiene el cuerpo deforme", "un deseo le cruzó la mente", "el cuchillo le desgarró la carne", "la droga le deterioró la mente”. En ese sentido, ¿cómo organizamos nuestra ontología?, ¿es la mente una cosa? El problema mente-cuerpo queda expresado, así, en los siguientes enunciados:

i) El cuerpo humano es un objeto material.

ii) La mente humana es un objeto espiritual.

iii) La mente y el cuerpo interactúan.

iv) El cuerpo y la mente no interactúan.

Ahora bien, existe el problema cuando hay razón para creer que una de las cuatro proposiciones es verdadera, ya que son incompatibles. Vid. Vélez, Juan Carlos, "Rechazo de la concepción dualista de la realidad mental", Revista Virtual, Universidad Santiago de Cali, 2008; VéLEz, Juan Carlos, "Teoría de la mente y estrategia intencional", Praxis Filosófica, $\mathrm{N}^{\circ}$ 26, enero-junio, 2008, pp. 63-82.

4 La tesis de la indeterminación está relacionada con otras tesis como la significación estimulativa, el holismo del significado y la naturalización de la epistemología. Para un acercamiento al tema, vid. Guerrero, Germán, “Teoría de la evidencia y holismo moderado en Quine”, Praxis Filosófica, № 8/9, 1999, pp. 389-416. 
referencia de Quine propuesta en 1960, en su libro Palabra y objeto. De acuerdo con Quine, son las consideraciones conductuales las que justifican las aproximaciones al significado $^{4}$; por ello, la epistemología debería reducirse a algo que cae por fuera de una filosofía fundacionalista, es decir, en una ciencia como la psicología. Lo que quiere decir es que el naturalismo consiste en "el reconocimiento de que la realidad se identifica y describe dentro de la ciencia misma y no en alguna filosofía previa" ${ }^{\text {. }}$. Por otro lado, afirma que la perspectiva naturalista se evidencia en el proyecto de una epistemología que denuncia el fracaso del empirismo de encontrar un fundamento para la ciencia natural basado en entidades mentales o datos puros de los sentidos; esta misma se debería concentrar en el objeto externo como punto de partida e indagar la cadena causal que va desde este hasta el cerebro.

Habría entonces dos tesis en Quine: que la epistemología forma un continuo con la ciencia, por lo tanto, no hay filosofía primera, y que la epistemología es solo un capítulo de la psicología (léase conductismo). De esta segunda tesis resalto la idea de que el hombre es un fenómeno natural, de ahí que en su estudio acudan tanto la epistemología como la psicología. Pero si consideramos, como lo hace Broncano ${ }^{6}$, que hay un hilo conductor que va del conductismo pasando por las diferentes formas de funcionalismo hasta llegar al conexionismo (disciplinas confederadas que hacen parte de las ciencias cognitivas), entonces el programa naturalista alcanza a la revolución cognitiva; esto, por supuesto, justifica la explicación científica de la ontología religiosa como dimensión cognitiva del ser humano. Lo que no estamos afirmando es que, al igual que el fracaso del empirismo que consistió en la imposibilidad de derivar estrictamente la ciencia a partir de la evidencia sensorial, que niega toda reducción posible, la ontología religiosa -como las creencias o la experiencia religiosa- se pueda reducir a elementos últimos o fundamentales pues ¿cuáles serían estos? Sin embargo, sí es necesario postular objetos intencionales, cuestión que abordaré más adelante.

La naturalización de la religión debería entonces observarse no desde su eliminación o reducción a ciencias como la antropología cognitiva, la sociobiología o la filosofía de la mente, sino más bien en el sentido de señalar que no es un saber fundado en principios teológicos a priori y, en consecuencia, que la continuidad epistemológica respecto de la religión ofrecería elementos para revisar empíricamente la estructura y origen de la ontología subyacente a las creencias religiosas. En otras palabras, estamos diciendo que para efectos de nuestra propuesta tomamos de Quine la idea de que la filosofía naturalista, plataforma desde la que pensamos el fenómeno religioso, forma un continuo con la ciencia natural. Así, "se propone clarificar, organizar y simplificar los conceptos más amplios y básicos, así como analizar (...) la evidencia dentro del marco de la ciencia misma. La

5 Quine, Willard V., Palabra y Objeto, Labor, Barcelona, 1995, p. 128.

6 Broncano, F., "La naturaleza del conocimiento en el conocimiento de la naturaleza", en Pérez, Diana I. (comp.), Los caminos del naturalismo. Mente, conocimiento y moral, Eudeba, Buenos Aires, 2002. 
frontera entre la filosofía y la ciencia natural es solo una cuestión de grado"7. No trataré la cuestión acerca de la naturalización de la normatividad en la teoría del conocimiento ni si el naturalismo necesita o no de la justificación; para ello, remito al lector al artículo de Broncano anteriormente citado.

Como ha puesto de relieve Diana Pérez $^{8}$, el naturalismo puede tomar caminos diversos como la tesis de la identidad, el reduccionismo, las teorías de la superveniencia y el emergentismo. En el caso de la propuesta que voy a defender, será simplemente una explicación natural, una suerte de continuidad epistemológica, no reduccionista, de la religión sin apelar a ganchos celestes. Ahora bien, como las ciencias cognitivas son la plataforma teórica desde la que argumentaré en lo sucesivo, y estas incluyen la biología, la teoría de la evolución y la psicología cognitiva entre otras, el tipo de preguntas planteadas serán: ¿qué presiones ejercidas por la selección natural favorecieron el impulso de la religión, a pesar de que, en términos del principio de economía, la religión es derrochadora y la naturaleza se caracteriza por eliminar el despilfarro?, ¿por qué los seres humanos ayunan, se arrodillan, hacen genuflexiones, se autoflagelan, golpean paredes con la cabeza, hacen cruzadas, o, de otra manera, se recrean en costosas prácticas que pueden consumir la vida, y en algunos extremos, acabar con ella? ${ }^{9}$

\section{La modularidad de la mente}

Una nueva manera de plantear el debate característico del siglo XVII entre racionalistas y empiristas es desde la pregunta por los mecanismos de desarrollo de la mente: ¿es la mente un sistema unitario de conocimiento o es un conjunto de sistemas especializados en diferentes problemas? Desde la perspectiva de Piaget, al igual que la del conductismo, todos los contenidos psicológicos -tales como memoria, percepción, etc.- se procesan de igual manera, dado que hay leyes universales de aprendizaje; es decir, la mente humana consta de procesos cognitivos de carácter general. Por tanto, este enfoque de concebir la mente como un dispositivo universal para resolver variados problemas y tareas se opone al modularismo. Quienes, por otro lado, defienden una definición modular de la mente sostienen que esta consiste en un conjunto de procesos de dominio específico, algo así como una navaja suiza en la que cada elemento desempeña una función especializada. Actualmente, la balanza se ha inclinado hacia la idea de que con los ladrillos hechos de conocimiento construimos conocimiento, es decir, hacia la naturaleza modular de la mente.

La teoría de la modularidad se asienta sobre el enfoque de la psicología cognitiva, y esta, a su vez, sobre las firmes bases del naturalismo en la filosofía de la mente. La teoría

7 Quine, W., op. cit., p. 135.

8 Vid. PÉrez, Diana, “Introducción: 'Naturalismo' se dice de muchas maneras, en Los caminos del naturalismo. Mente, conocimiento y moral, Eudeba, Buenos Aires, 2002.

9 Vid. Dawkins, Richard, El espejismo de Dios, Espasa, Madrid, 2007. 
de la modularidad afirma que los procesos cognitivos pueden ser mejor comprendidos si se asignan propiedades específicas a los componentes de procesamiento o módulos. La noción de modularidad está fuertemente relacionada con el lenguaje de la programación de sistemas y desde aquí se supone que los distintos componentes del sistema exhiban ciertos grados de independencia. Un rasgo importante de la tesis de la modularidad es que los componentes son autónomos y esta autonomía se hace evidente cuando otros componentes del mismo sistema fallan ${ }^{10}$. La teoría de la modularidad de la mente tiene su origen en los estudios sobre el tema de las capacidades perceptivas de los bebés, el origen innato de la capacidad del lenguaje que propuso Chomsky, la relación entre biología evolutiva y la resolución de problemas sociales y físicos que tuvo que resolver el hombre del pleistoceno, y por supuesto, la filosofía de la mente de Jerry Fodor.

Son aceptadas desde Chomsky las explicaciones modulares para las funciones del lenguaje. El estudio de las alteraciones del lenguaje oral ha permitido un cierto avance en la comprensión modular de los procesos lingüísticos: es el caso de la agnosia fonológica auditiva. También están los trastornos de lectura y escritura, en los que las diversas dislexias y los correspondientes errores semánticos son explicables mediante modelos modulares ${ }^{11}$.

Sin embargo, ha sido Fodor quien introdujo de manera sistemática la modularidad a la arena del debate en la filosofía de la mente; según este filósofo, la mente está compuesta por módulos que consisten en sistemas de entrada de datos que procesan un tipo de información de manera automática y, sobre todo, no consciente; precisamente por ello los módulos tienen una naturaleza computacionalmente encapsulada respecto de otros módulos. Por esta razón, cada sistema procesa información mecánica, química, táctil, visual y linguístico-semántica, pero lo importante es que la información de los diferentes módulos es enviada a un procesador central. La mente (procesador central) solo tiene acceso al resultado de la información producida, no a la información específica de los módulos. Por esta razón Fodor dirá que existen procesos denominados de pensamiento, reflexión, inteligencia o conciencia que acceden al cálculo computacional de los módulos haciendo que estos sean impermeables a lo que pensemos o creamos, optimizando la capacidad de respuesta de los módulos. Estos sistemas centrales no son modulares en el sentido antes aludido: "un módulo es un sistema informático, encapsulado desde el punto de vista de la información (...), especificado innatamente en gran parte (...) y asociado de forma característica con mecanismos neuroanatómicos específicos. (...) son rápidos, perceptivos, encapsulados respecto a la mayor parte del entorno, organizados alrededor de un flujo de información de abajo-arriba, y específicos de dominio"12. Por el contrario, el carácter no modular de los sistemas centrales de la mente queda expresado funcionalmente por el au-

10 PARkin, Alan J., "La neuropsicología como ciencia”, en Exploraciones en neuropsicología cognitiva, Editorial Médica Panamericana, 2004.

11 Idem.

12 Fodor, Jerry A., The Modularity of Mind, MIT, Cambridge, 1983, p. 3-4; versión en español: La Modularidad de la mente. Un ensayo sobre la psicología de las facultades, Morata, Madrid, 1986. 
tor cuando dice: "sin duda es importante atender a lo eternamente bello y verdadero, pero es más importante no ser comido. La naturaleza se las ha ingeniado para integrar ambas posibilidades - para lograr lo mejor de los sistemas rápidos y estúpidos, pero también de los más contemplativos y lentos, negándose sencillamente a optar entre ambos"13.

Para el tema que nos compete, solo es necesario hacer énfasis en la idea de que la organización de la mente se generó durante el largo camino de la evolución y no es propiedad exclusiva de nuestra especie. Fodor avala esta hipótesis al distinguir módulos perceptivos que tienen que ver con el procesamiento de información sensorial y módulos con propiedades de alto rendimiento cognitivo donde se asientan el razonamiento, el pensamiento, etc., en la carrera por la supervivencia.

Este tipo de posiciones naturalistas son cada vez más aceptadas en el estudio de la mente; así, por ejemplo, los psicólogos evolutivos Leda Cosmides y John Tooby ${ }^{14}$ sostienen que la mente es un órgano del cuerpo, es decir, que la mente es un mecanismo evolucionado que se ha ido ajustando y construyendo en respuesta a las presiones selectivas que nuestra especie ha tenido que afrontar durante su evolución. Steven Pinker también ha sostenido en su libro Cómo funciona la mente que la mente es un sistema de órganos de computación "diseñado por la evolución natural para resolver aquellos tipos de problemas con los que enfrentaron nuestros antepasados en su modo de vida como cazadores-recolectores", en particular, y en esto quiero hacer énfasis, "en el conocimiento y manejo de objetos, animales, plantas y otros individuos de la misma especie"15.

\section{a) Extensión de la Modularidad}

Para los propósitos de mi argumentación, la teoría de la modularidad en perspectiva evolucionista es el soporte que le sirve a la hipótesis de la religión como un subproducto de las funciones modulares de la mente. Al respecto, Richard Dawkins dice que "el comportamiento religioso puede ser un subproducto fallido y desafortunado de una propensión psicológica subyacente que, en otras circunstancias, es, o una vez fue, útil”16. Es decir, nuestros cerebros físicamente no han cambiado mucho desde la época de cazadoresrecolectores, pero sus funciones han sido reutilizadas para otros propósitos, no todos los cuales poseen un carácter claro de utilidad. Ha sido la acumulación de diseños sobre diseños a través de las generaciones en el largo proceso de la selección natural quien ha creado los sistemas funcionales de los organismos, y particularmente nuestra arquitectura

13 Citado por Mithen, Steven, "El big bang de la cultura humana: los orígenes del arte y de la religión", "Así pues ¿cómo ocurrió?, en Arqueología de la mente. Origenes del arte, de la religión y de la ciencia, Drakontos, Madrid, 1994.

14 Cosmides, Leda, y Tooвy, John, "Orígenes de la especificidad de dominio: la organización de la organización funcional” en Hirschfeld, Lawrence A., y Gelman, Susan A., (comp.), Cartografía de la mente. La especificidad de dominio en la cognición y en la cultura, Gedisa, Barcelona, 2002.

15 Pinker, Steven, Cómo funciona la mente, Destino, 1997, pp. 40-42.

16 Vid. Dawkins, R., op. cit. 
cognitiva, así que estos diseños de organización deben reflejar los principios y la lógica de la selección natural. Pero entonces, ¿cómo eran esos cerebros de nuestros ancestros, o más bien, cómo estaban organizados en términos funcionales y modulares?

La naturaleza modular de la mente consiste en la especificación de funciones especializadas de cada módulo cuyo funcionamiento, al interactuar con el entorno, fue configurado gradualmente por el proceso de la selección natural, a fin de resolver problemas de distinta índole; estos problemas son como sub-tareas de un gran problema genético, el de maximizar un número de copias que pasan a la siguiente generación. Como afirman Cosmides y Tooby, los mecanismos cognitivos actuales fueron determinados por los problemas adaptativos de los hombres durante la época del pleistoceno. Dicen que "la historia exitosa de la reproducción de los homínidos (incluyendo la reproducción de la especie) requirió el cumplimiento de una red de condiciones preliminares y facilitaciones para la reproducción en complejos entornos ecológicos y sociales"17. Como ejemplo de problemas adaptativos proponen recolectar para comer, orientarse en el espacio, elegir un compañero, ser padres, participar en el intercambio social, manejar las amenazas externas, evitar los predadores, evitar las toxinas de las plantas, evitar el incesto, entre otros. Es en ese sentido que argumentan los autores que un mecanismo de dominio general no hubiese podido comportarse de manera adaptativa y resolver los problemas del contexto ancestral. Un sistema de dominio específico de la información para resolver tareas concretas no está limitado a la estructura de dominio específico que presenta el mundo; así por ejemplo, los procedimientos aplicados a las arañas, el habla, los objetos, las madres, y las entidades autopropulsadas no podrían ser de dominio general, puesto que los individuos actuarían por ensayo y error al ver una serpiente o ante el hecho tener relaciones sexuales entre hermanos, es decir, el costo sería muy alto. Cosmides y Tooby resaltan el argumento de la pobreza del estímulo chomskiano señalando que "la percepción por sí misma no puede proveer por sí misma a los niños la lista de restricciones que afectan a la gramática humana"18.

Sin embargo, ello no significa que los módulos, aunque dependan de un programa genético, dependan de un gen responsable de cada rasgo. Aunque la mente es una adaptación diseñada por el proceso de selección natural no debe suponerse que todo cuanto sentimos, percibimos, o pensamos sea una adaptación biológica. Como ha señalado Pinker"19, "evolucionamos a partir de los simios, pero ello no significa que tengamos la misma mente que los monos".

Por ejemplo, tenemos un módulo para la percepción de superficies que trabaja bajo el supuesto de que "el mundo se halla iluminado de modo uniforme y suave", es decir, resuelve problemas que tienen que ver con la superficie terrestre; contamos también con

17 Cosmides, L. y Tooby, J., op. cit., p. 135.

18 Ibidem, p. 142.

19 Pinker, S., op. cit., p. 42. 
módulos motores para resolver problemas de cinemática (geometría del movimiento) y de dinámica (los efectos de la fuerza), vitales para un cuerpo que necesita contraer los músculos para mover el cuerpo. Más importante aún para los propósitos de nuestro argumento, existe un módulo que nos permite inferir cuáles son las creencias y deseos de la gente a partir de lo que hacen y, al contrario, permite predecir lo que harán a partir de la atribución de creencias y deseos. Este supuesto de asumir que las personas son objetos con mente es lo que se ha denominado psicología intuitiva, y es uno de los rasgos más importantes a la hora de dibujar el perfil de las presiones selectivas que condujo al proceso de hominización, a saber, el mundo social ${ }^{20}$.

¿Existen teorías intuitivas innatas o módulos para las diferentes maneras en que se interpreta el mundo? Muchos científicos cognitivos piensan que sí, que tenemos módulos especializados para los objetos y las fuerzas, para los seres animados, los artefactos, las mentes y los reinos naturales como animales, plantas y minerales. Lo importante aquí es que las personas pueden mezclar y ajustar sus modos de conocimiento, "lanzar una intención \{psicología intuitiva\} a un movimiento \{física intuitiva\}" el argumento que necesitamos para presentar una explicación para las creencias en dioses de todas las culturas: adjudicar intencionalidad a cosas o fenómenos que de hecho no los tienen.

Actuar, razonar o percibir exigen otros procesos mentales, como en el caso del lenguaje. No hay una inteligencia general. Así como se habla de unos cómputos mentales que constituyen la gramática universal, cada una de las restantes facultades tiene su propio diseño que es universal. Tales facultades humanas no nacen del consenso y fraternidad de la humanidad, sino que son descubrimientos reales sobre la especie humana y tienen un carácter biológico y genético; aquí se excluye el relativismo. ¿Cuáles son los módulos de la mente humana? En El instinto del lenguaje, Pinker ha señalado los siguientes:

- Mecánica intuitiva: conocimiento de fuerzas y deformaciones que experimentan los objetos.

- Biología intuitiva: comprensión del funcionamiento de las plantas y animales.

- Mapas mentales de territorios extensos.

- Psicología intuitiva: predicción del comportamiento de los demás a partir de creencias y deseos.

- Peligros: emociones como el miedo y la precaución; fobias ante estímulos como las alturas, la reclusión.

- Contaminación: incluyendo la emoción de desagrado, reacciones a ciertas cosas desagradables.

20 Vid. Gomila, A., "Evolución y Lenguaje”, en Broncano, F. (Ed.), La mente humana, Trotta, Barcelona, 1995.

21 Pinker, S., op. cit., p. 408. 
- Control y vigilancia del bienestar: emociones de felicidad y tristeza, estados de insatisfacción e inquietud.

- Justicia: sentido de derechos, obligaciones y faltas, con emociones asociadas de rabia y venganza.

- Emparejamiento sexual: sentimientos de atracción sexual, amor e intenciones de fidelidad y traición ${ }^{22}$.

Daniel Dennett ofrece otra clasificación de los módulos compartidos por muchas sociedades primitivas, a saber: dispositivo de detección de agentes (el otro que me está mirando ¿atacará o huirá?); adopción de la perspectiva intencional (relacionado con la psicología popular: seres que recuerdan y olvidan, piensan y esperan, rompedores de promesas) ${ }^{23}$.

¿Hay acaso una fiebre de modularitis? Enesco y Delval ${ }^{24}$ así lo creen. Es posible que haya, según esto, una "biología de sentido común" innata que tiene que ser diferente de los artefactos construidos por el hombre. Con este módulo atribuimos ciclos de vida y muerte a los seres vivos. Los cazadores-recolectores disponen de nombres para cientos de plantas y animales, así como de la ecología y su comportamiento. Sin embargo, para estas sociedades no existen dos mundos distintos, uno de personas (sociedad) y otro de cosas (naturaleza), sino un solo mundo - un medio- lleno de poderes personales y que incluye a los seres humanos, los animales y las plantas de los que dependen, y el paisaje en el que viven y se mueven.

Precisamente en este punto cobra cada vez más importancia la tesis del antropólogo Steven Mithen, quien ha señalado que, a partir de la incorporación del lenguaje, este actuó como un medio que generó lo que se ha denominado fluidez cognitiva, enlazando los distintos módulos de manera que la información de uno se solapa con la de otro. Una vez que los humanos primitivos empezaron a hablar, no pudieron dejar de hacerlo. Retazos del lenguaje social se filtraron hacia el módulo del mundo natural, creando nexos entre los diferentes módulos. Este fenómeno explicaría el surgimiento del animismo y el antropomorfismo, es decir, la personificación de objetos físicos inanimados. Ahora pasemos a las críticas.

\section{b) Críticas a la mente modular y las capacidades de dominio específico}

La teoría de la modularidad de la mente se fundamenta en la hipótesis de que existen estructuras cognitivas innatas en los bebés para saber, por ejemplo, si los seres humanos

22 Pinker, Steven, El instinto del lenguaje, Alianza, Madrid, 1994, pp. 462-463.

23 Vid. Dennett, Daniel, Romper el hechizo. La religión como fenómeno natural, Katz, Buenos Aires, 2006.

24 Vid. Enesco, Ileana, y Delval, Juan, "Módulos, dominios y otros artefactos", Infancia y Aprendizaje. Journal for the study of education and development, Vol. 29, 2006, Debate: "La Modularidad a debate". 
tienen mente, y de paso reconocer intercambios sociales; para identificar rostros humanos; para predecir el movimiento de los objetos por vías no obstruidas (solidez), incluyendo que los objetos se mueven hacia abajo en ausencia de soporte (gravedad) y la inercia. Aquí surge la pregunta acerca de si los módulos son predeterminados o existe un proceso de modularización; en apoyo a esta última idea, algunos autores afirman que la naturaleza plástica del cerebro es capaz de crear ilimitados circuitos neuronales, de tal manera que este no se encuentra preestructurado sino que desarrolla circuitos neuronales funcionales en interacción con el medio interno y externo.

La crítica que hacen Enesco y Delval -en el texto ya citado- ataca justo en la interpretación que se hace de los experimentos llevados a cabo con bebés de la que se concluye la organización modular innata de estos. El experimento mencionado se ha denominado violación de expectativas y consiste en crear situaciones en las que se transgrede alguna ley física, como la impenetrabilidad de los objetos debido a su solidez. Aquí, lo que se pretende demostrar es que si los bebés tienen algún principio fundamental de la ley física entonces se sorprenderían al ser este transgredido; el criterio escogido para probar la hipótesis es el tiempo de la mirada del bebé ante dicha situación. Si se queda mirando más de lo normal, se interpreta como si efectivamente se sorprendiera.

Enesco y Delval han acusado de adultomorfismo la adjudicación de un módulo para objetos físicos en el bebé y proponen explicaciones más simples como capacidades perceptivas a partir de contrastes visuales en vez de capacidades conceptuales. Los autores sostienen que el fracaso y el éxito de los bebés al resolver diferentes tareas no se debe interpretar como si midiesen competencias cognitivas similares, por ejemplo, la representación de objetos en el tiempo y en el espacio. En ese sentido, sus desaciertos se pueden deber a la escasa agudeza visual; sin embargo, dicen, es mejor mirar estos éxitos y fracasos como problemas distintos abordados actualmente por enfoques basados en sistemas dinámicos, los que precisamente muestran que los bebés son sensibles al contexto y la experiencia, y, por tanto, sus habilidades evolucionan con la práctica. Siguiendo a Varela (1992), dicen que el conocimiento no consiste en principios, sino que se encuentra encarnado o embebido en el entorno. Los autores de la crítica también debilitan la noción de modularidad masiva atacando el argumento de las disociaciones mentales, pero aquí no lo abordaré. De todas formas, la pregunta que se hacen es: ¿cuántos dominios o módulos hay?, ¿cómo explica la teoría de la modularidad de la mente la plasticidad cerebral, la capacidad adaptativa del ser humano histórico y cultural? Al final sostienen que los dominios de conocimiento se deben asumir no como punto de partida, sino como el resultado del desarrollo o la interacción de múltiples causas encadenadas, donde es borroso el límite entre lo biológico y la experiencia.

Me apresuro a señalar que si el niño no estuviera limitado por ciertos conocimientos previos, el aprendizaje sería imposible; además, sabemos que en cuanto más evolucionado es un organismo, más disposiciones innatas especializadas posee. Pero dejemos a un lado 
esta discusión sobre si las capacidades de dominio específico, además de ser modulares, son innatas o no. Entremos por fin en materia.

\section{Religión naturalizada}

Ya tenemos algunos elementos conceptuales y teóricos para empezar a armar nuestro rompecabezas naturalista de la religión, pero antes déjenme decir unas palabras que justifican mi empresa compartida por muchos otros autores en diferentes áreas de conocimiento.

Las religiones desempeñan un papel demasiado importante en las vidas de las personas, así como en la forma en que las sociedades se integran: incluso Darwin y Freud eran conscientes de su papel como pegamento social. Robert Hinde, psicólogo, plantea que los elementos por los que las personas se adhieren a las religiones son consecuencia de características psicológicas panculturales, la mayoría con fuerte sesgo emocional, que explican los rasgos comunes de la multiplicidad de los sistemas religiosos como los conocemos ${ }^{25}$.

Los aspectos positivos y negativos de las religiones no se pueden ignorar: nadie dudaría en asentir en su uso para perpetuar la injusticia, justificar la tortura a partir de las diferencias religiosas y generar innumerables guerras, en contraste con el hecho de ser la fuente de inspiración para el genio de las grandes obras musicales, y en general artísticas; de ofrecer gran cantidad de valores en el mundo, aportando, de paso, propósitos y sentido a la vida de miles de personas, así sea ofreciendo repuestas inverificables, por ejemplo, al tema de la muerte. Desde este punto de vista, quizás abordar la cuestión desde una perspectiva darwiniana sea incompleto. Según Hinde, “(...) la religión es algo más que la creencia en un dogma, y un análisis darwiniano de los sistemas religiosos necesita una aproximación más sutil de la que él le otorga" ${ }^{26}$. Aunque tiene razón en cierto sentido, aún no alcanzo a ver la esterilidad del enfoque de la evolución por selección natural. Ha olvidado Hinde que su propia disciplina, la psicología evolutiva, es una disciplina afortunada al recuperar e integrar las tesis del darwinismo. Ese es el nivel de análisis por el que abogo.

De igual modo, esto nos lleva a la pregunta naturalista que nos hemos formulado anteriormente: ¿puede la ciencia explicar la religión? Pregunta que antes de responder muchas personas solicitarían primero responder a esta otra: ¿debería la ciencia estudiar la religión? Algunos consideran que se corre un gran riesgo, y que sería mejor dejar las cosas como están, tal como solícitamente había dicho el biólogo Stephen Jay Gould: la ciencia y la religión tienen propósitos, metodologías y objetivos diferentes, y cada cual a lo suyo.

25 Hinde, Robert A., Por qué persisten los dioses. Una aproximación cientifica a la religión, Biblioteca Buridán, Barcelona, 2001.

26 Ibidem, p. 15. 
Solución conciliadora que no convence en esta época de curiosidad e información ilimitada, por no mencionar los compromisos éticos que conlleva.

Al contrario de Gould y de quienes defienden esos puntos de vista restrictivos, considero que en la comprensión del fenómeno religioso podríamos ganar mucho más que lo que arriesgaríamos. Al respecto, Dennett dice que "es hora de que sometamos a la religión como un fenómeno global, a la más intensiva investigación interdisciplinaria concebible, convocando además a las mejores mentes del planeta. ¿Por qué? Porque la religión es demasiado importante para nosotros como para que permanezcamos en la ignorancia respecto de ella. No solo afecta a nuestros conflictos sociales, políticos y económicos, sino también al significado que damos a nuestras vidas"27. Pero ¿cuáles son los riegos?, ¿qué tanto se verían afectadas las personas al mostrarles las consecuencias de un estudio semejante? Esta empresa tendría dificultades. Matthew Alpert, fundador de la neuroteología, afirma que "tratar de convencer a alguien que está programado para creer en una realidad espiritual de que esta no existe, puede ser como tratar de convencer a un esquizofrénico de que las voces que escucha provienen de su cabeza y no de una realidad externa" 28 .

Pero claro, alguien diría que la experiencia religiosa no es una disfunción química mientras que la esquizofrenia sí lo es; éticamente, la pregunta es ¿qué se ganaría o perdería si se enseñan los argumentos evolutivos del origen de las creencias religiosas, o simplemente a razonar acerca de lo sobrenatural? Alpert lo expresa así: ¿qué pasaría si reconociéramos que estas creencias no representan ninguna realidad trascendental, sino que realmente son la manifestación de percepciones erróneas generadas en nuestro interior, es decir, que Dios es un fantasma cognitivo? Estoy de acuerdo con él en que habría más libertad de explorar las nuevas posibilidades de un paradigma nuevo, con lo cual, al alimentar nuestro sentido de la existencia sobre las sólidas bases del naturalismo y el materialismo, redefiniríamos nuestro destino. Una ciencia de la religión sería de gran utilidad, puesto que ello podría reorientar políticas, responder a preguntas o generar progreso en nuestro mundo; no es una calamidad moral, y hay que reconocer que hay una enorme ausencia de información acerca del fenómeno religioso.

Sin embargo, ¿por qué muchas personas siguen considerando como una falta de respeto o sacrilegio el que sus creencias religiosas sean examinadas bajo el microscopio de las ciencias? Estoy convencido, como dice Dennett, de que el hechizo del carácter intocable de la religión debe ser roto. Apelar a la tradición para defender a la religión de un estudio detallado es un tabú que ningún ciudadano culto de nuestro siglo XXI estaría dispuesto a aceptar. Así que prosigamos con nuestro estudio.

27 Dennett, D., op. cit., p. 34.

28 Vid. Alpert, Matthew, Dios está en el cerebro. Una interpretación cientifica de la espiritualidad humana y de Dios, Norma, Barcelona, 2006. 
Párrafos más arriba, habíamos hablado de algunas características generales de la religión como la representación de seres sobrenaturales. Pascal Boyer, antropólogo cognitivo, en relación con la línea de argumentación que he estado defendiendo, atribuye el conjunto de representaciones mentales de la ontología religiosa propio de los sistemas culturales no a un proceso exhaustivo de socialización, sino a la existencia de rasgos cognitivos de dominio específico inherentes a nuestra arquitectura mental, lo cual explicaría el carácter universal de las creencias religiosas.

La pregunta aquí es: ¿por qué un tipo de representación se transmite más fácilmente que otras teniendo en cuenta sus propiedades estructurales?, ¿por qué las personas encuentran plausibles las representaciones religiosas? Pensemos que las cosas, los seres y los procesos ordinarios tal como los conocemos a través del sentido común son distorsionados completamente en las religiones. Allí tenemos seres invisibles pero situados en el espacio; intangibles, pero capaces de interactuar mecánicamente sobre objetos físicos; seres que no nacen, se desarrollan ni mueren. En ese sentido la ontología religiosa es extraordinaria en relación con la ontología del mundo cotidiano, pero eso es precisamente lo que la hace aceptable; es decir, el hecho de que viole las expectativas de hechos biológicos y físicos. Tener estas expectativas sobre el comportamiento de los objetos es la condición para representar los estados propios de las postulaciones religiosas.

Según Boyer ${ }^{29}$, el dominio de las representaciones se puede dividir en repertorios de representaciones: ontológico, que tiene que ver con entidades no observables (idea de un creador distante, impersonal, que habita en el cielo o espíritus que habitan los ríos); causal, es la conexión o relación causal entre el repertorio ontológico y los hechos observables; acción o episodios, son acciones o interacciones conectadas con los repertorios causal y ontológico como se observa en las acciones rituales; $y$ social, que tiene que ver con la identificación de roles entre las personas, como aquellas quienes realizan las acciones rituales (sacerdotes, chamanes, imanes). La hipótesis de Boyer es la siguiente: las representaciones religiosas se configuran a partir de ciertas presunciones y principios de conocimiento, y estos principios son fundamentales para explicar la adquisición y transmisión de las representaciones religiosas (RR).

Al tomar como ejemplo las ideas religiosas de los "Fang", que son diversas presunciones acerca de fantasmas o antepasados, coincide con Dennett al destacar como supuesto fundamental para producir generalizaciones la intencionalidad; dice que se considera que los fantasmas desean la efectuación de ciertos ritos. Se piensa que ellos saben que si una persona está afectada por una desgracia, en algún momento se verá forzada a llevarlos a cabo. Se dice entonces que deciden "enviar" alguna enfermedad a los vivos. El estudio del

29 Vid. BOYER, Pascal, "Restricciones cognitivas sobre las representaciones culturales: ontologías naturales e ideas religiosas", en Cartografía de la mente. La especificidad de dominio en la cognición y la cultura, Gedisa, Barcelona, 2002. 
autor indica que el comportamiento de los fantasmas es descrito y se infiere de unos principios psicológicos tácitos. La antropología tradicional y la sociología no tienen en cuenta estos principios, ya que están ancladas en el mito de la tabula rasa. En apoyo a la teoría de la modularidad de la mente, Boyer afirma que las presunciones se aplican a dominios ontológicos tales como objetos físicos, artefactos, seres vivientes y personas; su estructura son estos principios organizados en categorías como evento, objeto, ser viviente, animal y humano, que se organizan tempranamente y son independientes entre sí. Aquí la experiencia juega un papel secundario, como en los experimentos con niños de tres y cuatro meses.

Las violaciones de las presunciones acerca de esta clase de seres sobrenaturales son, en primer lugar, aquellas que los hacen objetos físicos extraños, como su invisibilidad e intangibilidad, cambios en su localización o ubicuidad; en segundo lugar, las presunciones biológicas, es decir, estas entidades no mueren o no han nacido, o no crecen -así, por ejemplo, los dioses no tienen una edad como resultado de cambios en el tiempo-; la tercera violación tiene que ver con las extrañas capacidades psicológicas, como el detectar pensamientos e intenciones a distancia.

En consecuencia, para albergar estas ideas religiosas acerca de entidades sobrenaturales basadas en propiedades contraintuitivas, se necesita de una plataforma de teorías intuitivas, basadas en el sentido común, que tienen una explicación evolutiva y modular, las cuales también pueden ser transferidas, como en el caso de los dioses griegos que son eternos pero tienen creencias y deseos. Según Boyer, "una categoría religiosa se describirá como cognitivamente óptima si: i) contiene alguna violación explícita del pensamiento de sentido común, y ii) hace un uso explícito de los principios intuitivos del conocimiento de sentido común" ${ }^{30}$.

Por lo tanto, las representaciones religiosas más fácilmente aceptadas serán aquellas que logren un equilibrio entre las bases intuitivas inferenciales y las violaciones de las teorías intuitivas, es decir, entre los requerimientos de la imaginación (potencial para llamar la atención) y que tengan potencial inferencial. Lo que quiero recalcar aquí es que no es posible asignar las características exigidas por Boyer si no se admite una plataforma modular de dominio específico, pues ello anclado en las expectativas de sentido común es lo que las representaciones religiosas violan en términos de expectativas. Pero entonces, ¿cómo relacionamos la teoría de la violación de expectativas con su origen evolutivo en términos de subproductos o exaptaciones?

¿Cuál es entonces el origen de algunas de las creencias religiosas, como los seres sobrenaturales que las pueblan, la existencia del alma inmortal, o una vida después de la muerte? El primer paso es la intencionalidad. Dennett llama la atención sobre este aspecto de la adscripción de intencionalidad o psicología popular a las personas, algo tan importante para nuestra supervivencia debido a la construcción de alianzas en grupos de homínidos cada vez más numerosos hasta el punto de que cuando alguien moría, y debido a las 
creencias basadas en dualismos, se seguía tratando al cadáver como un agente invisible, como una persona virtual con creencias y deseos. Scott Atran, antropólogo, no puede ver la religión, en ese sentido, como un proceso adaptativo, porque no observa sus beneficios a la supervivencia del individuo. Los comportamientos derivados de las representaciones religiosas son costosos en términos de la evolución que minimiza costos. Por ello, observa que si los creyentes piensan que cuando una persona muere, aún cuando el cuerpo ya se ha descompuesto y desaparecido, este individuo continúa llorando, riendo, sintiendo las cosas como si estuviese todavía vivo. Para él, es altamente improbable que la mutación genética baste para que esa característica sobreviviera basándose simplemente en una adaptación. Entonces, ¿en qué consiste precisamente su valor adaptivo?

Cuando alguien del grupo moría, la tarea consiguiente era la de actualización cognitiva, esto es, reactualizar nuestros hábitos, pues hay un sistema intencional menos. La adscripción de intencionalidad se traduce en la idea de propósito, es decir, si se trata de mantenerse con vida en un entorno donde las fuentes de alimento son bastante codiciadas, donde otros individuos compiten por aparearse, llevar alimento a sus hijos, donde el peligro y los riegos están a la vuelta de la esquina, así como los fenómenos naturales como sequías, tormentas, incendios, inundaciones, estos son hechos que hay que aprender a evitar o buscar según el caso. Se hace necesario una estrategia cognitiva de predicción en términos de que todo tiene en últimas un propósito, pues en cada caso yo también los tengo. El paso a la idea de Dios es casi inevitable.

Puede imaginarse fácilmente que un espíritu incorpóreo se mueve hacia algún otro lugar tras la muerte del cuerpo. También podemos fácilmente imaginar la existencia de una deidad superior como espíritu puro, no como propiedad emergente de una materia compleja, sino existiendo de forma independiente de la materia; aunado todo esto a la teleología natural infantil tenemos que, si todo tiene un propósito, el propósito tiene que ser de alguien: Dios ${ }^{31}$.

La selección privilegió, de ese modo, la teleología y el dualismo en los cerebros de nuestros antepasados. Asumir la estrategia intencional significa un atajo para predecir lo que un individuo hará, frente a otras opciones de predicción como la estrategia física y la estrategia de diseño. La teoría supone un organismo, sistema o agente y un observador, que hace las veces de intérprete; el punto de vista de un intérprete que adopta una estrategia predictiva de la conducta. Es decir, asume una actitud intencional. Esta es descrita por Dennett de la siguiente manera:

30 Ibidem, p. 214.

31 Dawkins, R., op. cit., p. 198. 
Primero se decide tratar al objeto cuyo funcionamiento hay que predecir como un agente racional; luego se deduce qué creencias debería tener ese agente, dada su posición en el mundo y su objetivo. Más tarde se deduce qué deseos tendría que tener siguiendo las mismas consideraciones, y por fin, se predice lo que este agente racional actuaría para conseguir sus metas a la luz de sus creencias ${ }^{32}$.

Desde la estrategia intencional en relación con el dualismo se asume no que una entidad está diseñada con un propósito, sino que detrás de tal propósito hay un agente invisible que guía sus acciones. Dawkins al respecto ha comentado que la postura intencional es un mecanismo cerebral que acelera la toma de decisiones en momentos en que es crucial para la vida misma. Es evidente que los niños y los hombres primitivos adjudican intenciones mentalistas al tiempo, las olas, la lluvia; incluso en nuestro caso, hacemos lo mismo con las máquinas o artefactos. Pero ello no significa que se tome la adscripción de propósitos como una adaptación en el sentido darwiniano.

La tesis fundamental es la siguiente: no todo rasgo observable y funcional es explicable en términos adaptacionistas; existen algunos, como el color rojo de la sangre o el vuelo de las aves, que son exaptaciones, accidentes desde el punto de vista biológico, como dijo alguna vez Stephen Jay Gould.

Por ejemplo, escribe Marantz Henig en el Times, los espacios debajo de las escaleras no poseen ninguna función en sí mismos, sin embargo, si construimos un armario allí, transformamos lo accidental en funcional. 'La selección natural hizo grande al cerebro humano pero la mayoría de nuestros potenciales y propiedades mentales puede que sean enjutas, es decir, consecuencias no adaptativas que surgieron al construir un aparato con una estructura tan compleja', escribió Gould ${ }^{33}$.

¿Son las creencias en lo sobrenatural y las religiones enjutas evolutivas? Muchos estudiosos de la evolución así lo creen. Las creencias en dioses, extraterrestres, ángeles, demonios y la permanencia del alma después de la muerte vendrían a ser subproductos que se originaron de funciones diversas más importantes y que se han modificado en otras funciones debido a la cultura. Los diversos módulos en que se organiza la mente para realizar funciones específicas como el comportamiento de los sistemas biológicos, físicos y sociales, gracias al lenguaje, se reorganizaron accidentalmente y terminaron albergando

32 Dennett, D., op. cit., p. 29. Para más detalles acerca de la estrategia intencional en relación con la teoría de la mente, vid. VÉLEZ, J. C., artículos citados.

33 Álvarez, Glenys, "Dios, una enjuta neuronal" (2009), disponible en http://www.sindioses.org/colGlenys/ glenys20090219.html. El artículo referido en el cuerpo de la cita es Henig, Robin Marantz, "Darwin's God", The New York Times, 4 de marzo de 2007, disponible en http://www.nytimes.com/2007/03/04/ magazine/04evolution.t.html?_r=1\&scp=1\&sq=darwin $\% 27 \mathrm{~s} \% 20 \operatorname{god} \& \mathrm{st}=\mathrm{cse}$. 
violaciones a las expectativas de sentido común que hoy conocemos como representaciones religiosas. En ese sentido, el origen de la representación o la creencia en Dios no es, como dice Mathew Alper, algo que surgió como una forma de mitigar la angustia de tener que vivir con la certeza de la muerte, o que era como una forma de llenar los vacíos epistémicos inexplicables por la ciencia. Aun cuando los estudios recientes en neuropsicología cognitiva y psicología evolutiva sugieren que su origen esté relacionado con procesos muy importantes para la supervivencia, sostengo que las representaciones religiosas que generan la ontología de los hechos extraordinarios son un accidente evolutivo, del que las personas, más tarde, fueron sacando provecho social, político, económico y psicológico. Seguimos transmitiendo dichas representaciones de generación en generación casi como mentes infantiles, creyendo que somos conscientes de ello, pero, en realidad, hay múltiples causas susceptibles de ser estudiadas por las ciencias. Es hora de darle una oportunidad al naturalismo como perspectiva del mundo y de nuestro lugar en él.

\section{Conclusiones}

Hemos visto, en primer lugar, los intentos de explicación de la creencia religiosa (principalmente la creencia en seres sobrenaturales) a través de la historia, y cómo el rasgo característico de estas diversas representaciones incluyen la actitud intencional y la violación de expectativas. Pasamos luego a justificar la perspectiva naturalista de la explicación de los fenómenos religiosos. Allí expuse la necesidad de excluir puntos de partida a priori, propios de la filosofía de corte fundacionalista. De ese modo, se defiende la ontología religiosa desde la psicología evolucionista de la modularidad, cuya explicación permite estudiar el origen de muchas funciones psicológicas formadas en el lento proceso evolutivo. No obstante, sostengo que la modularidad presenta algunas dificultades, sobre todo en relación con el tipo de conocimiento o información y cómo es utilizada dada la naturaleza modular de la mente. En la última parte del documento, argumento desde un enfoque cognitivista que la ontología religiosa y las creencias que conlleva son un proceso que emerge de manera no consciente de nuestra arquitectura mental, diseñada por procesos darwinianos. Es decir, el origen de la creencia en Dios se puede explicar utilizando categorías de análisis como proceso, representación, cognición, intencionalidad, materialismo, etc. De este estudio se concluye que la creencia en Dios no es una adaptación biológica de nuestros cerebros, sino un proceso accidental que se alimentó de nuestra propensión psicológica a las violaciones de expectativas, a las violaciones de lo que cotidianamente podemos predecir. La creencia en la creencia de Dios es un evento natural, tan biológico y cognitivo como cualquier otro; susceptible, por tanto, de ser analizado desde una confederación de disciplinas denominadas ciencias cognitivas y cuya plataforma filosófica es el naturalismo**

*Artículo recibido: 9 de abril de 2012. Aceptado: 3 de julio de 2012. 
Dr. Juan CARlos Vélez

\section{Bibliografía}

Alper, Matthew, Dios está en el cerebro. Una interpretación científica de la espiritualidad humana y de Dios, Norma, Barcelona, 2008.

Álvarez, Glenys, “Dios, una enjuta neuronal” (2009), disponible en http://www.sindioses. org/colGlenys/glenys20090219.html.

BOYer, PASCAL, "Restricciones cognitivas sobre las representaciones culturales: ontologías naturales e ideas religiosas", en Cartografía de la mente. La especificidad de dominio en la cognición y en la cultura, Gedisa, Barcelona, 2002.

Broncano, Fernando, "La naturaleza del conocimiento en el conocimiento de la naturaleza”, en Pérez, Diana I. (comp.), Los caminos del naturalismo. Mente, conocimiento y moral, Eudeba, Buenos Aires, 2002.

Cassirer, Ernst, “Mito y religión”, en Antropología filosófica, Fondo de Cultura Económica, México, 1993.

Copleston, Frederick, Filosofía medieval. De san Agustín a Escoto, en Historia de la filosofía, Tomo II, Ariel, Barcelona, 1971.

Cosmides, Leda, y Tooby, John, "Orígenes de la especificidad de dominio: la organización de la organización funcional”, en Hirschfeld, Lawrence A. y Gelman, Susan A., Cartografía de la mente. La especificidad de dominio en la cognición y en la cultura (comp.), Gedisa, Barcelona, 2002.

Dawkins, Richard, El espejismo de Dios, Espasa, Madrid, 2007.

Dennett, Daniel, Romper el hechizo. La religión como fenómeno natural, Katz, Buenos Aires, 2007.

Enesco, Ileana y Delval, JuAn, "Módulos, dominios y otros artefactos", Infancia y aprendizaje. Journal for the study of education and development, Vol. 29, 2006, Debate: "La modularidad a debate".

FodOR, JERRY A., The modularity of mind, MIT, Cambridge, 1983; hay versión en español: La modularidad de la mente. Un ensayo sobre la psicología de las facultades, Morata, Madrid, 1986.

Gomila, Antoni, "Evolución y lenguaje”, en La mente humana, Broncano, Fernando (ed.), La mente humana, Trotta, Barcelona, 1995. 
GonzÁlez, William, y Muñoz, Alexander, "El problema de Dios”, en Módulo de filosofía moderna y contemporánea, Universidad del Valle, 2003.

Guerrero, Germán, “Teoría de la evidencia y holismo moderado en Quine”, Praxis Filosófica, Filosofía antigua, N. 8/9, 1999, Departamento de Filosofía, Universidad del Valle.

Hinde, Robert A., Por qué persisten los dioses. Una aproximación cientifica a la religión, Biblioteca Buridán, Barcelona, 2001.

Mithen, Steven, "El big bang de la cultura humana: los orígenes del arte y de la religión", en Arqueología de la mente. Orígenes del arte, de la religión y de la ciencia, Drakontos, Madrid, 1994.

"Así pues ¿cómo ocurrió?”, en Arqueología de la mente. Orígenes del arte, de la religión y de la ciencia, Drakontos, Madrid, 1994.

Parkin, Alan J., "La neuropsicología como ciencia", en Exploraciones en neuropsicología cognitiva, Editorial Médica Panamericana, 2004, pp.

Pérez, Diana I., “Introducción: 'Naturalismo' se dice de muchas maneras”, en Los caminos del naturalismo. Mente, conocimiento y moral, Eudeba, Buenos Aires, 2002.

Pinker, Steven, El instinto del lenguaje, Alianza, Madrid, 1999.

-------------, Cómo funciona la mente, Destino, Barcelona, 2001.

Quine, Willard V., Palabra y objeto, Labor, Barcelona, 1968.

VÉlez, Juan Carlos, "Rechazo de la concepción dualista de la realidad mental", Revista Virtual, Universidad Santiago de Cali, 2008.

,"Teoría de la mente y estrategia intencional", Praxis filosófica, $\mathrm{N}^{\circ} 26$, enero-Junio, 2008, Departamento de Filosofía, Universidad del Valle, pp. 63-82. 